\title{
Finance Math Game: Uma proposta lúdica interdisciplinar para Ensino de Educação Financeira com Scratch
}

\section{Fernando Lucas de Oliveira Farias, Elvis Medeiros de Melo, Juliana Lacerda da Silva Oliveira, Charles Andryê Galvão Madeira, André Maurício Cunha Campos}

Instituto Metrópole Digital - Universidade Federal do Rio Grande do Norte (UFRN) Av. Sen. Salgado Filho, 3000 - Lagoa Nova, CEP: 59.078-970 - Natal - RN - Brasil

\{fernandoo.mcp, elvismedeiros.mm, julacerda01\}@gmail.com, charleseimd.ufrn.br, andreddimap.ufrn.br

\begin{abstract}
Financial education - FE as a mandatory cross-curricular theme foreseen at the BNCC, aims to provide the student, from an early age, with the development of skills related to good consumption habits and financial planning; being a challenge the teaching practice its integration with the other disciplines of the curriculum. In this context, the "Finance Math Game" emerges as a playful interdisciplinary proposal for teaching FE with Scratch. The methodology used in conducting the experiment is guided by Design Thinking. The results obtained in the initial immersion phase and reaction evaluation indicate that the proposal is able to establish relationships between the dynamics of the Leisure technical course with the knowledge about FE, using computational thinking and Scratch as a potential technology.
\end{abstract}

Resumo. A educação financeira - EF como tema transversal obrigatório previsto na $B N C C$, tem como objetivo proporcionar ao estudante, desde cedo, o desenvolvimento de habilidades relacionadas a bons hábitos de consumo e planejamento financeiro, sendo um desafio a prática docente sua integração com as demais disciplinas do currículo. Neste contexto, o "Finance Math Game" surge como proposta lúdica interdisciplinar para ensino de EF com Scratch. A metodologia utilizada na condução do experimento é norteada pelo Design Thinking. Os resultados obtidos na fase de imersão inicial e avaliação de reação indicam que a proposta é capaz de estabelecer relações entre as dinâmicas do curso técnico de Lazer com os conhecimentos sobre EF, utilizando o pensamento computacional e Scratch como tecnologia potencializadora.

\section{Introdução}

Ao longo dos anos, tem ficado cada vez mais evidente que a Matemática é essencial na vida cotidiana. É um instrumento necessário para desenvolver as capacidades intelectuais que ajudam na estruturação dos raciocínios lógico e dedutivo, indispensáveis na resolução de problemas, tanto na vida social como no contexto escolar. O pensamento computacional, como afirma a Unesco (2015), é uma das competências para o Século XXI, e acaba se tornando um conteúdo potencializador de práticas que estimulam o raciocínio lógico, tornando as práticas com conteúdos mais significativas. Práticas de desenvolvimento do pensamento computacional tem se evidenciado no contexto brasileiro, e um exemplo é o uso do software Scratch em práticas de pensamento computacional integrado a conteúdos matemáticos. 
Ao pensar na Educação Financeira, trata-se de um tema curricular transversal, trazida como obrigatória pela Base Nacional Comum Curricular (BNCC), com o objetivo de ajudar o aluno, desde cedo, a desenvolver a capacidade de planejar sua vida, sua família, e tomar boas decisões financeiras. Ela também traz, dentro de seus objetivos de estudo que visa melhor compreensão do dinheiro e sua função na sociedade, da relação entre dinheiro e tempo, dos impostos em sociedades diversas, do consumo em diferentes momentos históricos, incluindo estratégias atuais de marketing [BNCC 2017], sugerindo um trabalho conjunto com demais disciplinas do currículo da Educação Básica.

Tendo em vista a problemática levantada, propusemos uma oficina para trabalhar o Pensamento Computacional utilizando o software Scratch com alunos do ensino médio Integrado de um instituto federal. Os estudantes já estudaram o conteúdo de Educação Financeira, e a atividade teve o objetivo de retomada de conceitos, assim como a construção de jogos com o Scratch.

\section{Educação Financeira e Pensamento Computacional}

Ao pensar na Educação Financeira como conteúdo transversal no ensino do pensamento computacional, Muniz Júnior (2010) entende que educar financeiramente um cidadão vai além de ensinar Matemática Financeira. Apesar de ser o assunto central e, portanto, necessário e indispensável, não é o suficiente. Educar financeiramente é uma ação muito mais ampla, que inclui: aprender matemática para compreender as situações financeiras; entender o comportamento do dinheiro no tempo; organizar conscientemente suas finanças (futuras) pessoais; discutir matematicamente o uso consciente do crédito; entender temas de economia como PIB, inflação e seus diferentes índices, IOF, IR dentre outros. Para a OCDE (2004) a educação financeira sempre foi importante aos consumidores, para auxiliá-los a orçar e gerir a sua renda, a poupar e investir, e a evitar que se tornem vítimas de fraudes. No entanto, sua crescente relevância nos últimos anos vem ocorrendo em decorrência do desenvolvimento dos mercados financeiros, e das mudanças demográficas, econômicas e políticas.

Há também pesquisas que envolvem a programação visual integrado a Educação Financeira. Experiências realizadas nos EUA demonstram que, ao programar no Scratch, os alunos desenvolveram a criatividade, habilidades intelectuais e o raciocínio lógico-dedutivo para aprendizagem de conteúdos curriculares [Velasquez et al 2015]. Silva, Almeida e Godoi e Silva (2016) propuseram um estudo preliminar sobre a criação de um design educacional para integrar o software Scratch ao processo de ensino e aprendizagem dos conteúdos relacionados à Economia Doméstica e Educação Financeira no ensino fundamental.

De acordo com Lima e Santos (2014, p. 313) o Scratch "é muito mais acessível do que outras linguagens de programação, isso acontece pela utilização de uma interface gráfica que permite que cada projeto seja montado como blocos de montar, lembrando o Lego". Ele potencializa o trabalho com as habilidades para o Século XXI [Farias e Motta 2016]. Segundo eles, o software de programação Scratch que é uma linguagem de programação que proporciona o desenvolvimento dos processos cognitivos por meio da interação do aluno com a ferramenta, e a potencialização de múltiplas competências de aprendizagem. Do ponto de vista conteudista em relação a matemática, eles destacam a Geometria e Coordenadas Cartesianas, bastante nítidas ao observarmos a interface de programação do Scratch. 
VIII Congresso Brasileiro de Informática na Educação (CBIE 2019)

Anais do XXV Workshop de Informática na Escola (WIE 2019)

\section{Objetivos}

Os objetivos da proposta levaram em consideração a Estratégia Nacional de Educação Financeira, que tem como finalidade a promoção da educação financeira e previdenciária, contribuindo para o fortalecimento da cidadania, a eficiência e solidez do sistema financeiro nacional e a tomada de decisões conscientes por parte dos consumidores [Brasil 2010]. A prática teve o como objetivo geral estabelecer relações entre as dinâmicas do curso técnico integrado em Lazer com os conhecimentos sobre educação financeira, utilizando o pensamento computacional e Scratch como tecnologia potencializadora.

\section{Metodologia}

A realização da prática educativa seguiu um plano de aula ${ }^{1}$ elaborado colaborativamente por uma equipe multidisciplinar constituída por profissionais das área de computação, educação e matemática que foram responsáveis pela definição da temática da intervenção, objetivos, conteúdos, sequenciamento didático, critérios de avaliação e resultados esperados.

Utilizamos o Mentimeter $^{2}$ para calibrar a imersão realizada acerca da importância e benefícios da educação financeira no cotidiano dos participantes, sendo que estes com seus smartphones enviaram seus feedbacks de forma interativa para cada questão apresentada, que por sua vez foram processadas e ilustradas pela ferramenta, ver Figura 1.

Figura 1. Nuvem de Palavras geradas pela ferramenta "Mentimeter"

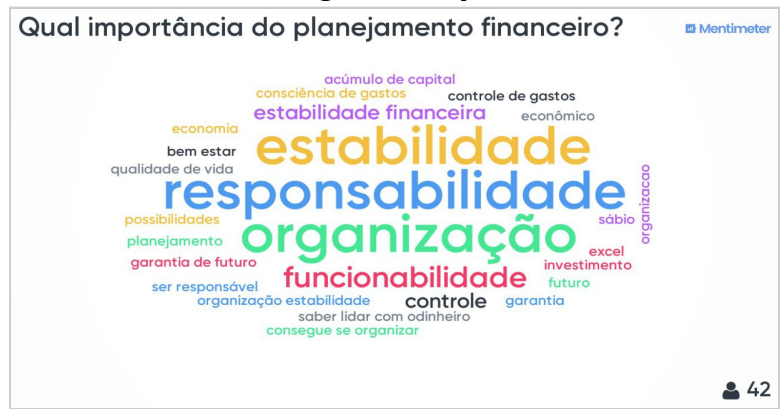

Logo em seguida, foi disponibilizado o material de apoio ${ }^{3}$ com referencial teórico, imagens, vídeos, áudios e projeto de exemplo ${ }^{4}$ desenvolvido na plataforma Scratch $^{5}$ intitulado "Finance Math Game - Montando seu Evento - Festa Infantil" que serviram de referência para desenvolvimento do projeto "Monte seu evento" construído pelos participantes.

Em seguida, os mediadores realizaram uma introdução à programação visual em blocos sequenciada nas temáticas. Os alunos foram imersos acerca dos principais recursos e funcionalidades da plataforma Scratch; apresentamos uma situação-problema que deveria ser resolvida através da construção de um jogo educativo, cujos os requisitos são descritos na Tabela 1.

\section{Tabela 1. Finance Math Game - Projeto Final}

\footnotetext{
${ }^{1}$ Disponível em: <http://bit.ly/2yTmPOe> Acesso em: 04 nov. 2018

${ }^{2}$ Disponível em: <http://mentimeter.com/> Acesso em: 04 nov. 2018

${ }^{3}$ Disponível em: <http://bit.ly/oficina-scratch-ifrn-material> Acesso em: 04 nov. 2018

${ }^{4}$ Disponível em: <http://bit.ly/oficina-scratch-ifrn-jogo> Acesso em: 04 nov. 2018

${ }^{5}$ Disponível em: <https://scratch.mit.edu/> Acesso em: 04 nov. 2018
} 
VIII Congresso Brasileiro de Informática na Educação (CBIE 2019)

Anais do XXV Workshop de Informática na Escola (WIE 2019)

\begin{tabular}{|c|c|}
\hline Problemática & $\begin{array}{c}\text { Jogo Educacional } \\
\text { Requisitos }\end{array}$ \\
\hline \multirow{11}{*}{$\begin{array}{l}\text { Você será encarregado de } \\
\text { desenvolver um jogo intitulado } \\
\text { "Monte seu Evento" que tem } \\
\text { como objetivo principal } \\
\text { disponibilizar uma lista de } \\
\text { serviços para um cliente, } \\
\text { possibilitando que ele } \\
\text { selecione os itens desejados } \\
\text { para sua festa dentro de um } \\
\text { orçamento pré-estabelecido, } \\
\text { orientando o cliente sempre } \\
\text { que possível para que não } \\
\text { exceda o seu orçamento } \\
\text { durante a compra dos itens. }\end{array}$} & Montar o cenário com background disponibilizado \\
\hline & Importar o Sprite "Cassy" que exibirá os diálogos com cliente \\
\hline & Importar os Sprites do menu serviços \\
\hline & Programar os diálogos da personagem Cassy \\
\hline & Programar o acesso às opções de serviços \\
\hline & Programar a compra de serviços com troca de mensagens \\
\hline & Validar para compras apenas dentro do orçamento \\
\hline & Criar variável para armazenar os dados do cliente \\
\hline & Criar variável para armazenar o valor da compra \\
\hline & Criar variável auxiliar para validar orçamento $\mathrm{x}$ valor compra \\
\hline & Programar animação durante a compra dos serviços \\
\hline
\end{tabular}

No desenvolvimento do projeto, os alunos foram orientados a constituírem times de até sete pessoas, a fim de realizar o desenvolvimento de um novo jogo educacional que deveria ter um dos seguintes temas: (i) Princesa; (ii) Super-heroí; (iii) Cantor ou (iv) Série/Desenho. Logo em seguida, os estudantes realizaram demonstração de seus projetos.

No encerramento da intervenção, foi realizada uma avaliação de reação com os participantes da oficina mediante um survey ${ }^{6}$ que teve como objetivo principal, coletar informações acerca da percepção dos estudantes sobre a experiência intitulada "Finance Math Game", enquanto proposta interdisciplinar para educação financeira através da construção de jogos com scratch. Os resultados são promissores e apresentados na seção 5 deste trabalho.

\section{Resultados e Discussões}

Bem como análise dos conhecimentos, habilidades e atitudes desenvolvidos durante a proposta interdisciplinar que de forma profícua, permitiu estabelecer relações entre as dinâmicas do curso técnico em Lazer com os conhecimentos sobre a educação financeira, utilizando o pensamento computacional e o Scratch como tecnologia potencializadora.

A retomada de conceitos da matemática financeira, aliada a introdução de boas práticas correlatas à educação financeira no início da intervenção, permitiu aos aprendizes refletirem sobre a importância da educação financeira em sua vida cotidiana, melhor compreensão da importância do planejamento financeiro, reflexão sobre os comportamento negativos e positivos identificados durante a realização de compras em seu anfêmero.

Identificamos na enquete interativa realizada com Mentimeter, que apesar de familiarizados com conceitos e premissas da educação financeira; grande parte dos estudantes manifestam diversos comportamentos negativos: Quero comprar tudo (23\%); Não pesquiso o

\footnotetext{
${ }^{6}$ Disponível em: <http://bit.ly/oficina-scratch-ifrn-avaliação> Acesso em: 04 nov. 2018
} 
preço; Fico ansioso (19\%); Compro coisas desnecessárias (16\%) como os mais citados. O que apesar de surpreendente foi interessante, uma vez que o projeto final intitulado "Monte seu Evento" teve como proposta por meio da construção de um jogo educacional no Scratch sensibilizar os aprendizes acerca da importância de não comprar tudo, considerando um orçamento pré-estabelecido; pesquisar os preços dos produtos e serviços da festa antes para verificar se o valor estava dentro das possibilidades do cliente; racionalizar a escolha dos itens que irão ser adquiridos para o evento, evitando a compra de coisas desnecessárias.

Ao final da intervenção após realizada apresentação dos projetos, os estudantes foram convidados a participar de uma avaliação de reação que teve como objetivo identificar sua percepção acerca da experiência intitulada "Finance Math Game", enquanto proposta interdisciplinar para educação financeira através da construção de jogos com Scratch. Dentre os resultados, observamos $71,5 \%$ dos participantes concordam que a prática educativa "Finance Math Game" permitiu planejar e executar ações envolvendo a criação de jogos digitais no controle de orçamento familiar e a educação financeira, enquanto que $71,4 \%$ indicam que a prática promoveu a reflexão crítica, acerca de conceitos relacionados a educação financeira.

Os resultados positivos são reflexo do engajamento dos estudantes no desenvolvimento do projeto final, que buscou justamente estabelecer requisitos que trabalhassem o controle do orçamento, pautado em premissas da educação financeira e promovendo a reflexão crítica nos estudantes quanto ao planejamento e execução de ações na programação de seus jogos.

\section{Considerações finais}

Não obstante, destacamos que a maior dificuldade reportada pelos aprendizes foi justamente o desconhecimento da plataforma Scratch, assim como, o pouco tempo de aula que tiveram para o desenvolvimento do jogo. Neste contexto, o uso do jogo como ferramenta de apoio aos processos de ensino e aprendizagem foi tida inicialmente como surpresa pelos participantes, contudo, majoritariamente manifestaram terem gostado da dinâmica e proposta interdisciplinar apresentados pelos pesquisadores do "Finance Math Game".

De maneira geral, a proposta foi avaliada como positiva, visto que os alunos conseguiram desenvolver seus jogos e compreender que o uso dos mesmos ajudam na construção e aprendizagem. Não obstante, o uso da programação proporcionou o desenvolvimento de importantes competências como colaboração, organização, protagonismo, criatividade, tomada de decisão.

\section{Referências}

Base Nacional Comum Curricular (BNCC). Disponível em: <http://basenacionalcomum.mec.gov.br>. Acesso em: 06 nov. 2018.

Lima, R. R.; Santos, M. B. (2014). Angry Birds no mundo das Funções Afim e Quadrática Aprendendo Matemática com Scratch. Encontro Regional de Estudantes de Matemática da Região Sul. Universidade Federal do Pampa. Rio Grande do Sul: Bagé, 2014.

Muniz Junior, I. (2010). Educação Financeira: Conceitos e Contextos para o Ensino Médio.

OCDE. Organização de Cooperação e de Desenvolvimento Econômico (2004). OECD's Financial Education Project. Assessoria de Comunicação Social.

Velazques, N. F. et al (2015). Novice Programmers Talking about Projects: What Automated Text Analysis Reveals about Online Scratch Users' Comments. 